\title{
Avaliação da qualidade da água de locais próximos às estrumeiras em propriedades rurais produtoras de leite do Vale do Taquari/RS
}

As propriedades produtoras de leite podem dispor os dejetos de três formas: propriedades sem estrumeira, propriedades com estrumeira fechada e sem cobertura e propriedades com estrumeira fechada e coberta. Esse trabalho teve como objetivo fazer a avaliação da qualidade da água em locais próximos às estrumeiras em propriedades produtoras de leite do Vale do Taquari/RS. Foram analisados parâmetros físicos e químicos: pH, oxigênio dissolvido, nitrogênio amoniacal total, temperatura, turbidez, cor verdadeira, sólidos totais dissolvidos e ferro, e parâmetros microbiológicos: coliformes totais, termotolerantes e Escherichia coli através da metodologia do Standart methods. Foi realizado um comparativo dos pontos a montante e a jusante às estrumeiras, além da verificação de diferenças nos níveis desses parâmetros em período quente (verão) e frio (inverno), meses de janeiro e junho, respectivamente, além de compara-los aos níveis estabelecidos pela Resolução CONAMA no $357 / 2005$ dispõe sobre a classificação dos corpos d'água e estabelece os limites dos parâmetros físicos, químicos e biológicos. Os resultados mostram que as análises dos parâmetros físicos, químicos e microbiológicos dos pontos montante e jusante das propriedades não demostraram diferenças estatísticas significativas. Além disso, os períodos frio e quente (janeiro e junho), também não alteram os níveis da maioria dos parâmetros. Os parâmetros físicos e químicos: $\mathrm{pH}$, temperatura e coliformes termotolerantes tiveram diferenças significativas nos períodos analisados, ocorrendo uma diminuição de seus níveis no mês de junho. Os parâmetros: oxigênio dissolvido, pH, sólidos totais dissolvidos e nitrogênio amoniacal total encontram-se dentro dos limites estabelecidos pela Resolução CONAMA no 357/2005 para todas as classes. Os níveis de ferro, encontram-se enquadrados em classe 3 para a maioria das amostras. Ferro e turbidez possuem amostras com níveis acima do estabelecido para todas as classes. A cor se encontra com niveis para a classe 2, já os parâmetros microbiológicos, coliformes termotolerantes e E. coli ficaram dentro do estabelecido para classes 3 ou 4 na maior parte das amostras. Pode-se concluir que a qualidade da água se encontra comprometida.

Palavras-chave: Parâmetros de água; Dejetos; Bovinocultura.

\section{Evaluation of water quality in places close to manure in rural properties producing milk in the Vale do Taquari/RS}

\begin{abstract}
Milk-producing properties can dispose of waste in three ways: properties without manure, properties with closed manure and without cover and properties with closed and covered manure. This work aimed to evaluate the water quality in places close to the manure on milk producing properties in Vale do Taquari/RS. Physical and chemical parameters were analyzed: $\mathrm{pH}$ dissolved oxygen, total ammonia nitrogen, temperature, turbidity, true color, total dissolved solids and iron, and microbiological parameters: total coliforms, thermotolerants and Escherichia dissolved oxygen, total ammonia nitrogen, temperature, turbidity, true color, total dissolved solids and iron, and microbiological parameters: total coliforms, thermotolerants and Escherichia
coli using the Standart methods methodology. A comparison was made of the points upstream and downstream to the manure, in addition to checking differences in the levels of these parameters in the hot (summer) and cold (winter) periods, January and June, respectively, in addition to comparing them to the levels established by CONAMA Resolution no $357 / 2005$ provides for the classification of water bodies and establishes the limits of physical, chemical and biological parameters. The results show that the analysis of the physical, chemical and microbiological parameters of the points upstream and downstream of the properties did not show significant statistical differences. In addition, the cold and hot periods (January and June) also do not change the levels of most parameters. The physical and chemical parameters: $\mathrm{pH}$, temperature and thermotolerant coliforms had significant differences in the analyzed periods, with a decrease in their levels in the month of June. The parameters: dissolved oxygen, $\mathrm{pH}$, total dissolved solids and total ammoniacal nitrogen are within the limits established by CONAMA Resolution No.357/2005 for all classes. Iron levels are classified as class 3 for most samples. Iron and turbidity have samples with levels above the established for all classes. The color meets levels for class 2, whereas the microbiological parameters, thermotolerant coliforms and E. coli were within the established for classes 3 or 4 in most samples. It can be concluded that the water quality is compromised.
\end{abstract}

Keywords: Water parameters; Waste; Cattle farming.

Topic: Desenvolvimento, Sustentabilidade e Meio Ambiente

Reviewed anonymously in the process of blind peer.

\section{Thais Müller (iD}

Universidade do Vale do Taquari, Brasil

http://lattes.cnpq.br/3548029451429303

http://orcid.org/0000-0001-7366-9678

thais_muller84@hotmail.com

\section{Mônica Jachetti Maciel (id}

Universidade do Vale do Taquari, Brasil

http://lattes.cnpq.br/2575088289818885

http://orcid.org/0000-0002-6863-2181

monicajm@univates.br

\section{Claudete Rempel}

Universidade do Vale do Taquari, Brasil

http://lattes.cnpq.br/8340497822227462

http://orcid.org/0000-0001-8573-0237

crempel@univates.br
Received: 04/12/2019

Approved: 12/01/2020
Referencing this:

MULLER, T.; MACIEL, M. J.; REMPEL, C.. Avaliação da qualidade da água de locais próximos às estrumeiras em propriedades rurais produtoras de leite do Vale do Taquari/RS. Revista Ibero Americana de Ciências Ambientais, v.11, n.1, p.362-377, 2020. DOI: http://doi.org/10.6008/CBPC2179-6858.2020.001.0033 


\section{INTRODUÇÃO}

A agropecuária pode ser entendida como a junção das atividades de agricultura, pecuária, silvicultura, exploração vegetal e pesca (FEE, 2017). O Brasil possui como uma das suas principais atividades a agropecuária leiteira, sendo o quarto produtor mundial de leite, ficando atrás dos Estados Unidos, Índia e China (FAO, 2016). Em 2016, o país produziu 33,62 bilhões de litros, sendo a região Sul, responsável por $37,0 \%$ do total nacional (IBGE, 2017). A produção de leite nessa região consolidou-se como atividade âncora na composição da renda dos agricultores, impactando no desenvolvimento regional e se mostrando promissora (JUNG et al., 2017). Dentre os estados que compõem a região Sul, o Rio Grande do Sul, tem na produção de leite mudanças relevantes no ambiente econômico e social (MARION FILHO et al., 2011). O estado se destaca sendo o terceiro maior produtor de leite no país, responsável por $13,7 \%$ da produção nacional (IBGE, 2017).

A região do Vale do Taquari no RS, local de estudo do presente trabalho, destaca-se na produção de leite estadual. Estando localizado na mesorregião Centro Oriental Rio-Grandense, que atualmente é composto por 36 municípios, os quais, em sua maioria, possuem economia baseada no setor primário com agropecuária, sendo a produção de leite uma das principais atividades e com maior potencial para o seu desenvolvimento (REMPEL, 2009). Essa região é também conhecida como o Vale dos Lácteos (BORTOLI et al., 2016), pois tem como uma de suas principais atividades econômicas a agropecuária leiteira e responde por $8 \%$ da produção estadual de leite in natura (FEE, 2015).

As atividades da agropecuária leiteira, como as demais atividades humanas, podem gerar altos teores de contaminação ambiental devido aos dejetos produzidos. A quantidade de matéria-orgânica desses dejetos, quando dispostos de forma inadequada pode causar impacto e sobrecarregar o solo, sendo lixiviados e podendo contaminar os corpos d'água. Essas atividades são vistas como vilãs do meio ambiente, pelo seu potencial em causar danos (BORTOLI et al., 2015).

Segundo Bortoli et al. (2016), os dejetos produzidos nas propriedades leiteiras do Vale do Taquari, podem ser acondicionados sem estrumeiras ou em estrumeiras do tipo fechadas e cobertas ou ainda, em estrumeiras fechadas e sem cobertura. Esse trabalho teve como objetivo fazer uma avaliação da qualidade da água em locais próximos às estrumeiras em propriedades produtoras de leite do Vale do Taquari/RS. Foram avaliados parâmetros físicos e químicos: pH, oxigênio dissolvido, nitrogênio amoniacal total, temperatura, turbidez, cor verdadeira, sólidos totais dissolvidos e ferro e parâmetros microbiológicos: coliformes totais e termotolerantes e Escherichia coli dos locais próximos às estrumeiras. Foi realizado também um comparativo dos pontos a montante e a jusante, além da verificação de diferenças nos níveis desses parâmetros, entre verão e inverno, respectivamente, janeiro e junho. A Resolução CONAMA no 357/2005 (BRASIL, 2005), foi utilizada nesse estudo, pois dispõe sobre a classificação dos corpos de água superficiais e das diretrizes ambientais para o seu enquadramento. Os dados analisados nas propriedades foram comparados aos níveis estabelecidos para os parâmetros, constantes nessa resolução. 


\section{METODOLOGIA}

Essa pesquisa se classifica como quantitativa. Quanto ao objetivo, a pesquisa é um estudo explicativo e quanto aos procedimentos técnicos é classificada como experimental com coleta de dados de forma longitudinal. Segundo Bortolli et al. (2016), de um total de 36 propriedades distribuídas entre 21 municípios do Vale do Taquari, 52,4\% (19 propriedades) possuem estrumeira fechada e coberta, 33,3\% (12 propriedades) fechada, porém sem cobertura e 14,3\% (5 propriedades) não possuem estrumeira. Para esse estudo foram selecionadas três propriedades rurais produtoras de leite de cada categoria para compor uma amostra (Quadro 1), sendo um dos critérios a proximidade com os cursos d'água, totalizando nove propriedades, sendo duas em Vespasiano Corrêa, duas em Encantado, uma em Roca Sales, três em Arroio do Meio e uma em Lajeado. A Figura 1 mostra os municípios que compõem o Vale do Taquari e os municípios onde ocorreram as coletas.

Quadro 1: Tipo de recurso hídrico e forma de acondicionamento dos dejetos para cada uma das propriedades produtoras de leite do Vale do Taquari - RS analisadas nesse estudo.

\begin{tabular}{|l|l|l|l|}
\hline Propriedade & Nascente & Categoria de acondicionamento & Caracterização quanto às redondezas \\
\hline A & Nascente & Estrumeira fechada e coberta & Interior, circundada por propriedades rurais. \\
\hline B & Córrego & Sem estrumeira & Interior, circundada por propriedades rurais \\
\hline C & Córrego & Estrumeira fechada e coberta & Bairro industrial \\
\hline D & Nascente & Sem estrumeira & Interior, circundada por propriedades rurais \\
\hline E & Córrego & Estrumeira fechada & Interior, circundada por propriedades rurais \\
\hline F & Córrego & Estrumeira fechada & Interior, circundada por propriedades rurais \\
\hline G & Córrego & Sem estrumeira & Interior, circundada por propriedades rurais \\
\hline H & Córrego & Estrumeira fechada e coberta & Bairro industrial \\
\hline I & Córrego & Estrumeira fechada & Interior, circundada por propriedades rurais \\
\hline
\end{tabular}

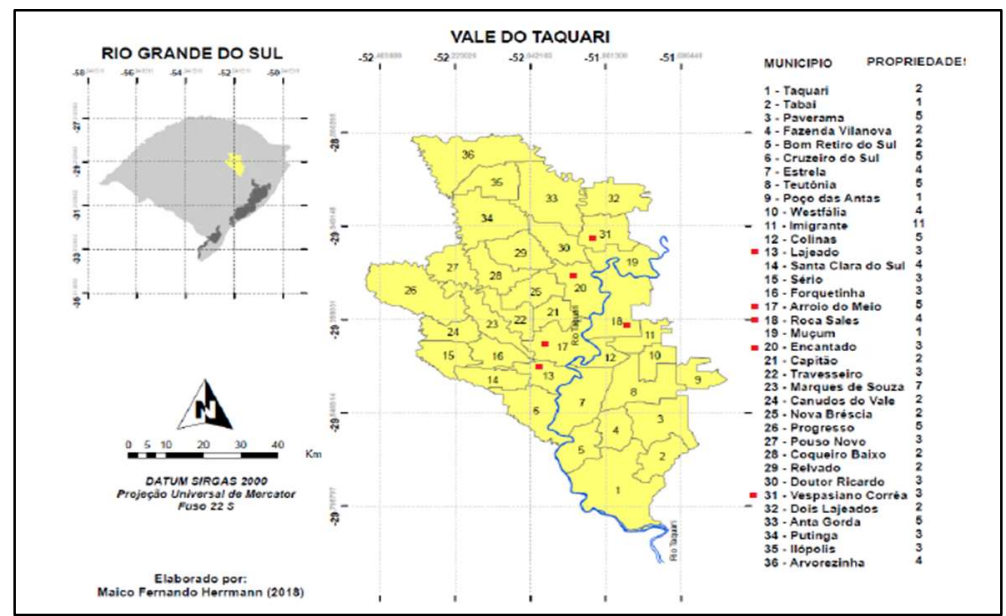

Figura 1: Localização e municípios que compõem o Vale do Taquari - RS com o número de propriedades estudadas no projeto 'Sustentabilidade em propriedades produtoras de leite'.

Os cursos d'água das propriedades analisadas nesse estudo possuíam largura variando de alguns centímetros (10 a $15 \mathrm{~cm}$ ) até no máximo 1,5 metros (córrego na propriedade C), com profundidades de 15 centímetros a mais ou menos 1 metro. Os cursos d água das propriedades B, C, F, possuem mata ciliar preservada, ainda que com extensão menor que o estabelecido pela legislação, Lei $n^{\circ} 12.651$, Novo Código florestal, de 25 de maio de 2012 (BRASIL, 2012), que deve ser de no mínimo 30 metros para cursos com a largura existentes nessas propriedades. Essas propriedades, porém, enquadram-se em passivo ambiental, tendo a extensão da mata ciliar reduzida. Nas propriedades $A, H, I$, a mata ciliar está brevemente preservada, 
sendo que na propriedade A, essa preservação é observada apenas no ponto a jusante. Já nas propriedades D, E, e G as margens estão completamente degradadas, não existindo mata ciliar.

Nas propriedades A, D, F, os cursos d’água são utilizados, eventualmente, para a dessedentação animal. Segundo a Resolução CONAMA 357/2005, as águas para essa finalidade precisam ser enquadradas no máximo até a classe 3 . Nos demais locais, esses cursos passam pela propriedade, mas não são por ela utilizados. Os cursos d’água das propriedades C e I são utilizados para atividade de recreação como banho e pesca, em locais vizinhos às propriedades.

Os locais de coleta foram os cursos d água próximos aos locais onde ficam os animais e as estrumeiras ou os dejetos produzidos na propriedade nos casos em que não há estrumeira. As coletas ocorreram a montante e a jusante às estrumeiras ou dejetos, em dois momentos: no verão, caracterizando o período quente (janeiro) e inverno, caracterizando o período frio (junho) do ano de 2019. As amostras de água foram armazenadas em frascos de vidro esterilizados de $100 \mathrm{~mL}$ (para as análises microbiológicas) e dois frascos de $500 \mathrm{~mL}$ de plástico, sendo um para as análises de nitrogênio amoniacal total e cor verdadeira e o outro para a análise de ferro. As amostras foram transportadas até os laboratórios de microbiologia e de biorreatores da Univates em caixa de isopor com gelo para manter a temperatura ideal. As análises foram realizadas no mesmo dia da coleta, respeitando o prazo de 24 horas e em triplicata a partir de uma única coleta. As análises de $\mathrm{pH}$, temperatura, oxigênio dissolvido, turbidez e sólidos totais dissolvidos foram realizadas in loco, com a utilização da Sonda multiparâmetros U-52G (Horiba). Para as análises de cor verdadeira, a amostra foi filtrada e foi utilizado o equipamento colorímetro portátil Digimed DM-COR. A análise de Nitrogênio amoniacal total seguiu a metodologia $4500-\mathrm{NH}_{3} \mathrm{C}$ do Standard Methods (APHA, 2012). O ferro seguiu a metodologia descrita em Standard Methods - Método 3500 Fe - B Fenantrolina (APHA, 2012).

As análises microbiológicas foram realizadas através da técnica do Número Mais Provável (APHA, 2012) e no Manual Prático de Análise de Água da Fundação Nacional de Saúde (FUNASA) (BRASIL, 2013), que consistem em dois testes, um presuntivo e outro confirmativo. Para a realização da prova presuntiva foi executada a inoculação de $10 \mathrm{~mL}$ das amostras em três tubos contendo Lauril sulfato de sódio (OXOID) em concentração dupla. Em seguida foi adicionado $1 \mathrm{~mL}$ de amostra em outros três tubos contendo Lauril sulfato de sódio (OXOID) em concentração simples. Para finalizar, foi realizada uma diluição de concentração $10^{-1} \mathrm{e}$ foi adicionado $1 \mathrm{~mL}$ em mais uma série de 3 tubos Lauril sulfato de sódio (OXOID) em concentração simples, totalizando 3 séries de 3 tubos com diferentes concentrações da amostra. Os resultados de NMP foram expressos a partir do Standard Methods. Na prova confirmativa (coliformes totais) foi realizado o repique das amostras nos tubos que apresentaram reação positiva no teste presuntivo que foi indicado através da formação de gás nos tubos de Duran, para tubos contendo caldo Verde Brilhante Bile 2\% Lactose (OXOID) que foram incubados a $36 \pm 1$ ㄷ C por 48 horas. Os tubos que apresentaram formação de gás no teste Verde Brilhante Bile 2\% foram repicados para o caldo Escherichia coli (EC) e permaneceram em banho-maria por 48 horas, na temperatura de $45 \pm 0,2 \stackrel{\circ}{ } \mathrm{C}$. Para diferenciação de $E$. coli foi adotado o procedimento com utilização de substrato fluorogênico. Os tubos com formação de gás nos tubos de foram repicados para o caldo EC Mug (DIFCO), no qual permaneceram por $24 \mathrm{~h}$ a $44,5 \pm 0,5^{\circ} \mathrm{C}(\mathrm{APHA}, 2012)$. Foram então visualizados quanto à 
formação de fluorescência sob lâmpada UV. O Quadro 2 apresenta os valores estabelecidos para os parâmetros, sendo que alguns não possuem valores estabelecidos para determinadas classes.

Quadro 2: Níveis estabelecidos para os parâmetros avaliados nesse estudo em suas determinadas classes conforme a Resolução CONAMA n³57/2005.

\begin{tabular}{|l|l|}
\hline PARÂMETROS & NÍVEIS \\
\hline Cor verdadeira & No máximo $75 \mathrm{mg}$ Pt/L para classe 2 \\
\hline Nitrogênio total & Até $13,3 \mathrm{mg} / \mathrm{L}, \mathrm{para}$ as classes, com influência do $\mathrm{pH}$. \\
\hline Oxigênio dissolvido & No mínimo $6 \mathrm{mg} / \mathrm{L}$ para classe $1,5 \mathrm{mg} / \mathrm{L}$ para classe 2 e $4 \mathrm{mg} / \mathrm{L}$ para classe 3 \\
\hline $\mathrm{pH}$ & De 6 a 9 para as classes 1, 2 e 3 \\
\hline Turbidez & No máximo 40 NTUs para a classe 1 e 100 NTUs para as classes 2,3 e 4 \\
\hline Ferro & Até 0,3 mg/L para classes 1 e 2, até $5 \mathrm{mg} / \mathrm{L}$ para classe 3 \\
\hline Sólidos totais dissolvidos & No máximo $500 \mathrm{mg} / \mathrm{L}$ para as classes 1,2 e 3 \\
\hline $\begin{array}{l}\text { Coliformes termotolerantes e. } \\
\text { coli }\end{array}$ & $\begin{array}{l}200 \text { para classe } 1,1000 \text { para classe } 2,2500 \text { para classe } 3 \text { (para usos de recreação e contato } \\
\text { primário) }\end{array}$ \\
\hline
\end{tabular}

Os dados foram tabulados em Microsoft Excel e analisados por meio de estatística descritiva e inferencial. As diferenças entre os períodos do ano e entre os pontos montante e jusante às estrumeiras foram comparadas por meio de ANOVA - 1 critério, utilizando-se 5\% como margem de erro, por meio do Programa BioEstat, versão 5.0.

\section{RESULTADOS}

Nas análises físicas e químicas da água do presente estudo pode-se verificar que os parâmetros pH e temperatura mostraram diferenças significativas nos pontos montante e jusante de janeiro (verão) em relação aos pontos montante e jusante de junho (inverno). Tanto a temperatura quanto o pH demonstram diminuição de seus valores no mês de junho (Figura 2), a montante em janeiro e junho (M1 e M2) e a jusante, também em janeiro e junho (J1 e J2). Os valores de pH a montante no mês de junho foram menores que os valores a montante no mês de janeiro. O mesmo ocorreu para a jusante, sendo que o mês de janeiro teve valores superiores ao mês de junho.

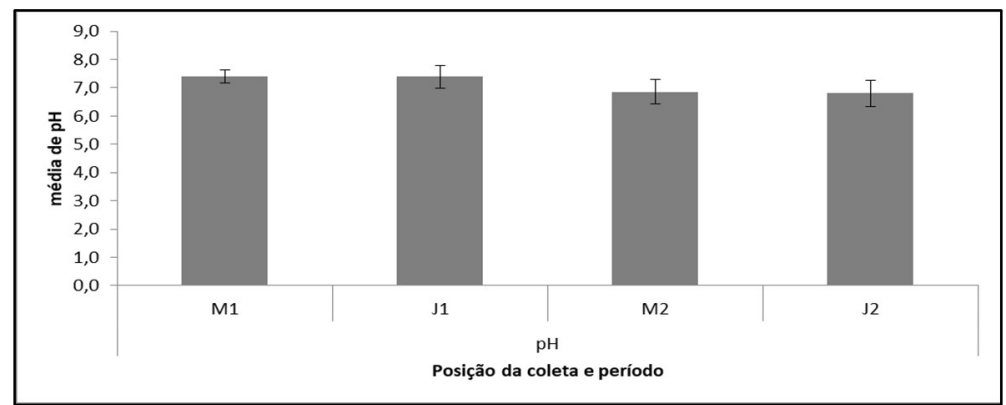

Figura 2: Média dos valores de pH dos pontos a montante e a jusante dos cursos d água dos locais próximos às estrumeiras nos dois períodos avaliados: verão (janeiro) e inverno (junho).

Média dos valores de $\mathrm{pH}$ da água dos pontos a montante e a jusante dos cursos d'água próximos às estrumeiras nos dois períodos avaliados: verão (janeiro) e inverno (junho), utilizando ANOVA - teste de Tukey, $p<0,05$ sendo M1montante janeiro; M2- montante junho $p=0,01$ e J1- jusante janeiro e J2-jusante junho $p=0,05$.

A média do valor do pH para o mês de janeiro ficou acima de 7,0 (7,4 montante 1 e jusante 1$)$ e no mês de junho, abaixo de 7,0 (montante $2=6,9$ e jusante $2=6,8$ ). A análise bioestatística demostrou também que não houve diferenças de $\mathrm{pH}$ das médias dos pontos montante e a jusante no mesmo período (janeiro e 
junho) nas propriedades analisadas, ou seja, a estrumeira ou o local da deposição de dejetos não interfere no $\mathrm{pH}$ da água que passa pela propriedade. Apesar disso, quando observado o valor do $\mathrm{pH}$ de cada amostra (Quadro 3), observa-se que todas ficaram dentro do limite estabelecido pela legislação que é de pH de 6 à 9 , para as águas de classes 1, 2 ou 3, segundo a Resolução do CONAMA n 357/2005 (BRASIL, 2005).

A análise bioestatística mostra diferença significativa na temperatura tanto a montante quanto a jusante dos locais onde estão as estrumeiras para os períodos analisados (meses de janeiro e junho), verificando-se uma diminuição da temperatura no mês de junho, algo já esperado em se tratando de um mês mais frio do que janeiro (Figura 3). Os valores médios da temperatura da água foram $22,8^{\circ} \mathrm{C}$ para a montante em janeiro (M1) e para a jusante em janeiro (J1), para o mês de junho a média das temperaturas verificadas foram de $17,2^{\circ} \mathrm{C}$ a montante (M2) e $17,0^{\circ} \mathrm{C}$ a jusante (J2), ou seja, menores que no mês mais quente (janeiro).

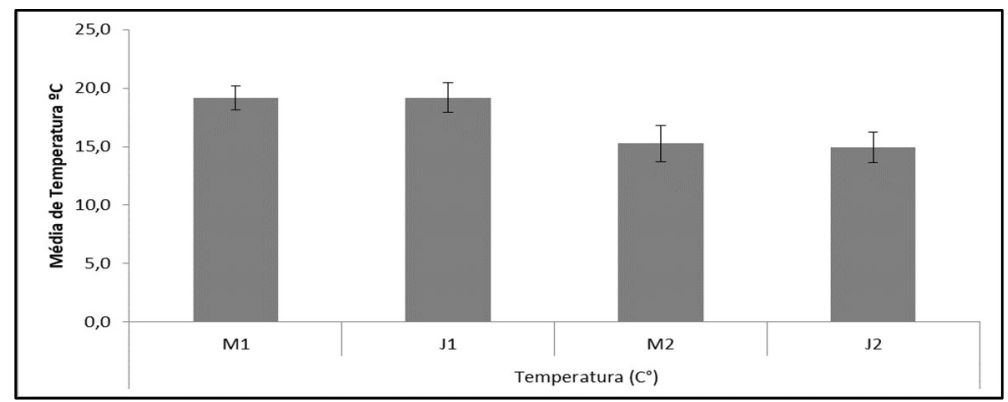

Figura 3: Média dos valores da temperatura $\left({ }^{\circ} \mathrm{C}\right)$ nos cursos d água a montante e a jusante dos locais próximos às estrumeiras nos dois períodos avaliados: verão (janeiro) e inverno (junho). Média dos valores da temperatura da água dos pontos à montante e à jusante dos cursos d'água próximos às estrumeiras nos dois períodos avaliados: verão (janeiro) e inverno (junho), utilizando ANOVA - teste de Tukey, $p<0,05$ sendo M1- montante janeiro M2- montante junho $p=0,01$ e J1- jusante janeiro e J2-jusante junho $p=0,01$.

Os demais parâmetros físicos e químicos, cor verdadeira, nitrogênio amoniacal total, sólidos totais dissolvidos, turbidez, oxigênio dissolvido e ferro não tiveram diferenças significativas nos pontos avaliados (montante e jusante) e nem entre os dois períodos (meses de janeiro e junho). Para o parâmetro cor verdadeira, conforme a Resolução do CONAMA n³57/2005 (BRASIL, 2005) o valor máximo estabelecido é de $75 \mathrm{mg} \mathrm{Pt} / \mathrm{L}$, para a classe 2. As análises de cor verdadeira demonstram que quase todas as propriedades possuem médias abaixo de $75 \mathrm{mg} \mathrm{Pt} / \mathrm{L}$, estando dentro do estabelecido também para a classe 2, com exceção apenas da amostra C no ponto a jusante no mês de janeiro (J1) que foi de $90 \mathrm{mg} \mathrm{Pt} / \mathrm{L}$, sendo esse o valor máximo entre todas as amostras.

As análises de sólidos totais dissolvidos, no presente estudo, mostraram que todas as amostras estão dentro do limite estabelecido pela legislação para a classe 2 , sendo que o estipulado é de até $500 \mathrm{mg} / \mathrm{L} \mathrm{para}$ as águas de classes 1, 2 ou 3. Os valores mínimo e máximo de STD encontrados nesse estudo foram, respectivamente, $0,0 \mathrm{mg} / \mathrm{L}$ para a amostra C no ponto jusante janeiro (J1) e $114,3 \mathrm{mg} / \mathrm{L}$ na amostra I no ponto montante no mês de janeiro (J1).

A turbidez mostrou-se alterada para algumas amostras. Os valores verificados para as amostras A e I no ponto a montante do mês de junho (M2) ficaram acima do limite estabelecido pela legislação (Resolução CONAMA n 357/2005) que é de no máximo 100 NTU (BRASIL, 2005). A amostra D (Quadro 4) no mês de junho tanto a montante (M2) como a jusante (J2) também possui valores acima dos limites estabelecidos, já 
a amostra $\mathrm{H}$, possui valores acima do estabelecido apenas a montante no mês de janeiro (M1).

Quadro 3: Resultados das análises dos parâmetros físicos e químicos temperatura, $\mathrm{pH}$, cor e sólidos totais dissolvidos (STD) para cada amostra nos pontos a montante no verão, em janeiro (M1) e no inverno, mês de junho (M2) e a jusante no verão, em janeiro (J1) e no inverno, em junho (J2) para cada uma das propriedades avaliadas.

\begin{tabular}{|c|c|c|c|c|c|c|c|c|}
\hline \multirow{2}{*}{$\begin{array}{l}\text { PARÂMETRO } \\
\text { PROPR. }\end{array}$} & \multicolumn{2}{|c|}{ Temperatura $\left({ }^{\circ} \mathrm{C}\right)$} & \multicolumn{2}{|c|}{$\mathrm{pH}$} & \multicolumn{2}{|c|}{$\operatorname{Cor}(\mathrm{Pt} / \mathrm{L})$} & \multicolumn{2}{|c|}{ STD (mg/L) } \\
\hline & M1 & M2 & M1 & M2 & M1 & M2 & M1 & M2 \\
\hline$A$ & 22,1 & 16,1 & 7,2 & 6,8 & 4,0 & 3,3 & 53,0 & 40,0 \\
\hline $\mathrm{B}$ & 21,7 & 15,4 & 7,1 & 6,6 & 20,8 & 9,0 & 39,0 & 35,0 \\
\hline C & 24,0 & 15,3 & 7,2 & 6,9 & 71,2 & 9,1 & 40,3 & 41,0 \\
\hline $\mathrm{D}$ & 24,7 & 16,9 & 7,4 & 7,2 & 27,8 & 21,3 & 110,3 & 87,0 \\
\hline$E$ & 21,5 & 17,9 & 7,5 & 6,4 & 38,5 & 19,2 & 71,7 & 6,9 \\
\hline $\mathrm{F}$ & 22,8 & 18,5 & 7,3 & 6,4 & 17,9 & 20,8 & 100,3 & 99,0 \\
\hline $\mathrm{G}$ & 22,3 & 18,2 & 7,5 & 7,1 & 18,0 & 20,5 & 83,3 & 71,3 \\
\hline $\mathrm{H}$ & 22,8 & 19,9 & 7,5 & 6,8 & 45,7 & 17,6 & 82,7 & 71,3 \\
\hline I & 23,1 & 16,3 & 7,8 & 7,7 & 26,5 & 13,0 & 114,3 & 87,0 \\
\hline PROPR. & J1 & $\mathrm{J2}$ & J1 & $\mathrm{J2}$ & J1 & $\mathrm{J2}$ & J1 & $\mathrm{J2}$ \\
\hline A & 21,6 & 15,8 & 6,7 & 6,4 & 5,2 & 1,6 & 44,7 & 36,0 \\
\hline$B$ & 21,7 & 15,4 & 7,0 & 6,7 & 20,9 & 10,0 & 38,3 & 35,0 \\
\hline C & 24,0 & 15,4 & 7,1 & 6,8 & 90,0 & 9,8 & 0,0 & 41,0 \\
\hline D & 25,4 & 17,0 & 7,9 & 7,4 & 49,6 & 12,0 & 102,3 & 84,0 \\
\hline$E$ & 21,6 & 18,1 & 7,3 & 6,5 & 41,1 & 18,1 & 75,7 & 72,0 \\
\hline $\mathrm{F}$ & 22,7 & 18,2 & 7,5 & 6,5 & 14,0 & 24,9 & 110,7 & 110,0 \\
\hline$G$ & 22,4 & 18,3 & 7,6 & 7,0 & 20,7 & 17,8 & 84,3 & 72,0 \\
\hline $\mathrm{H}$ & 22,9 & 18,6 & 7,5 & 6,4 & 45,7 & 26,3 & 80,7 & 73,7 \\
\hline I & 23,1 & 16,2 & 8,0 & 7,7 & 25,2 & 13,8 & 98,7 & 85,3 \\
\hline
\end{tabular}

(M1 - montante janeiro, M2 - montante junho, J1- jusante janeiro, J2 - jusante junho).

As análises de ferro mostraram que $72 \%$ das amostras (26 amostras) ficaram enquadradas na classe 3, que possui limite de $5 \mathrm{mg} / \mathrm{L}$ e apenas 6 amostras ficaram dentro dos limites para as classes 1 e 2 que é de 0,3 mg/L. Essas análises mostraram ainda que 6 amostras ficaram acima de todos os limites estabelecidos pela Resolução CONAMA 357/05, tendo como valor máximo 60,38 mg/L na amostra D a jusante no mês de janeiro (J1).

As análises de oxigênio dissolvido (OD) mostram que os valores de médios estão em todas os pontos acima dos limites mínimos estabelecidos pela legislação (Resolução CONAMA n 357/2005) que é de $6 \mathrm{mg} / \mathrm{L}$ para classe 1, $5 \mathrm{mg} / \mathrm{L}$ para classe 2 e $4 \mathrm{mg} / \mathrm{L}$ para classe 3 (BRASIL, 2005), assim estando todas dentro do limite para a classe 1 . O nível mais baixo detectado foi $7,2 \mathrm{mg} / \mathrm{L}$ na amostra $\mathrm{G}$, ponto montante em janeiro (M1). A amostra G foi coletada em um córrego cuja margem se encontra completamente degradada e sem cobertura vegetal, apenas uma pastagem em seu entorno, o que pode vir a interferir na qualidade dessa água causando a diminuição do oxigênio dissolvido nesse local, mesmo assim, encontra-se dentro do limite exigido pela resolução. Além disso, os valores das análises de nitrogênio amoniacal total $\left(\mathrm{N}-\mathrm{NH}_{3}\right)$ nesse estudo foram

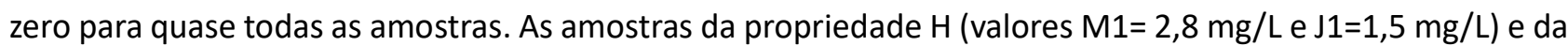
propriedade I (M1 = 1,4 mg/L), possuem valores dentro do estabelecido para classe 1 .

As análises dos parâmetros microbiológicos não apresentaram diferenças significativas nos pontos a montante e a jusante dentro da mesma propriedade e nem nos diferentes meses de coletas (janeiro e junho) para os valores de coliformes totais e E. coli. Já para os coliformes termotolerantes ocorrem diferenças significativas entre as médias dos pontos a montante (M1 e M2) e a jusante (J1 e J2) nos meses estudados, ou seja, existe uma diminuição da quantidade de coliformes termotolerantes no mês de junho em 
comparação ao mês de janeiro (Figura 4).

Quadro 4: Resultados das análises dos parâmetros físicos e químicos: nitrogênio amoniacal (N-NH3), oxigênio dissolvido (OD), turbidez e ferro para cada amostra nos pontos a montante no verão, em janeiro (M1) e no inverno, mês de junho (M2) e a jusante no verão, em janeiro (J1) e no inverno, em junho (J2) para cada uma das propriedades avaliadas

\begin{tabular}{|c|c|c|c|c|c|c|c|c|}
\hline PARÂMETRO & \multicolumn{2}{|c|}{ N-NH3 (mg/L) } & \multicolumn{2}{|c|}{$O D(\mathrm{mg} / \mathrm{L})$} & \multicolumn{2}{|c|}{ Turbidez (NTU) } & \multicolumn{2}{|c|}{ Ferro (mg/L) } \\
\hline PROPR. & M1 & M2 & M1 & M2 & M1 & M2 & M1 & M2 \\
\hline A & 0,0 & 0,0 & 9,5 & 14,1 & 10,8 & 800,0 & 0,7 & 0,1 \\
\hline B & 0,0 & 0,0 & 14,5 & 14,8 & 13,7 & 1,2 & 1,0 & 0,4 \\
\hline C & 0,0 & 0,0 & 30,0 & 27,1 & 76,5 & 0,6 & 6,4 & 0,2 \\
\hline $\mathrm{D}$ & 0,0 & 0,0 & 10,9 & 17,0 & 20,9 & 744,3 & 9,0 & 4,5 \\
\hline$E$ & 0,0 & 0,0 & 8,0 & 13,0 & 20,0 & 17,3 & 2,0 & 0,4 \\
\hline $\mathrm{F}$ & 0,0 & 0,0 & 8,4 & 12,1 & 14,4 & 4,2 & 0,8 & 0,8 \\
\hline G & 0,0 & 0,0 & 11,2 & 23,4 & 49,9 & 61,7 & 5,6 & 0,3 \\
\hline $\mathrm{H}$ & 2,8 & 0,0 & 11,5 & 9,5 & 649,2 & 97,5 & 2,6 & 2,2 \\
\hline 1 & 1,5 & 0,0 & 19,1 & 23,4 & 31,4 & 168,3 & 0,9 & 0,4 \\
\hline PROPR. & J1 & $\mathrm{J2}$ & J1 & $J 2$ & J1 & $J 2$ & J1 & $\mathrm{J2}$ \\
\hline A & 0,0 & 0,0 & 14,3 & 23,1 & 7,3 & 21,6 & 0,5 & 0,2 \\
\hline B & 0,0 & 0,0 & 9,3 & 15,9 & 8,7 & 26,4 & 0,9 & 2,2 \\
\hline C & 0,0 & 0,0 & 8,8 & 16,9 & 81,5 & 11,1 & 4,1 & 0,5 \\
\hline $\mathrm{D}$ & 0,0 & 0,0 & 8,2 & 11,7 & 0,0 & 263,3 & 60,4 & 0,6 \\
\hline$E$ & 0,0 & 0,0 & 13,1 & 17,4 & 23,2 & 6,1 & 2,1 & 0,7 \\
\hline $\mathrm{F}$ & 0,0 & 0,0 & 13,4 & 8,7 & 14,4 & 43,0 & 1,1 & 1,3 \\
\hline G & 0,0 & 0,0 & 7,2 & 22,4 & 70,8 & 4,4 & 6,6 & 0,3 \\
\hline $\mathrm{H}$ & 1,4 & 0,0 & 18,9 & 15,9 & 54,5 & 18,9 & 1,5 & 0,7 \\
\hline 1 & 0,0 & 0,0 & 23,2 & 23,1 & 77,2 & 72,9 & 2,8 & 0,3 \\
\hline
\end{tabular}

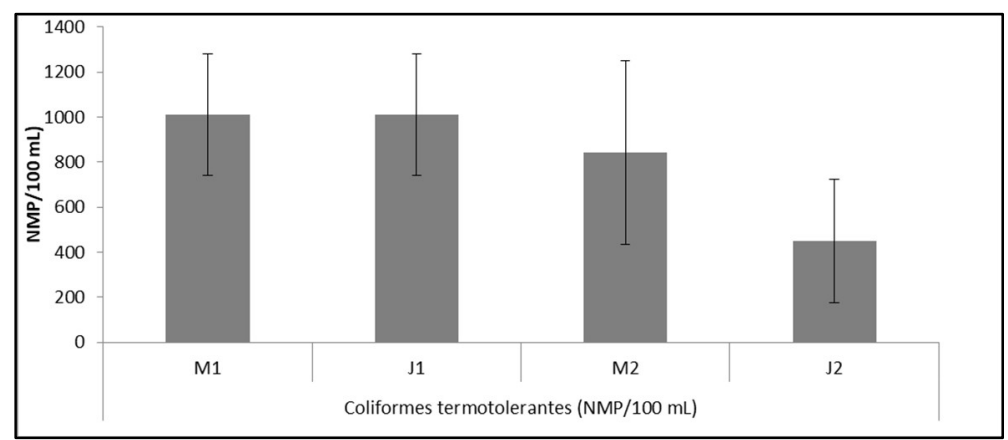

Figura 4: Média da quantidade de coliformes termotolerantes (NMP/100 mL) a montante e a jusante nos locais próximos às estrumeiras nos dois períodos avaliados: verão (janeiro) e inverno (junho).

Média da quantidade de coliformes termotolerantes dos pontos a montante e a jusante dos cursos d'água próximos às estrumeiras nos dois períodos avaliados: verão (janeiro) e inverno (junho), utilizando ANOVA - teste de Tukey, $p<0,05$ sendo M1- montante janeiro M2- montante junho $p=$ NS e J1- jusante janeiro e J2-jusante junho - $p=0,01$.

A diferença foi significativa também entre o ponto montante e jusante no mês de junho (M2 e J2), nos quais podemos verificar diminuição na quantidade de coliformes termotolerantes no ponto após as estrumeiras ou deposição dos dejetos, o que não está relacionado a isso, sendo que se houvesse influência, deveria ser observado um aumento (Figura 4). Os coliformes totais não possuem valores estabelecidos nessa resolução, sendo que esse grupo de microrganismos não indica necessariamente contaminação em água, pois inclui diversos gêneros e espécies de bactérias não entéricas e podem ser encontrados no solo e nos vegetais (MAGALHÃES et al., 2014). Os valores de coliformes termotolerantes estipulados na resolução podem ser usados como referência para a quantidade de Escherichia coli (BRASIL, 2005).

Ao analisar separadamente os resultados obtidos para os parâmetros microbiológicos nas amostras (Quadro 5), pode-se verificar que apenas a propriedade A ponto a montante 2 em janeiro (M2) e a 
propriedade $\mathrm{H}$, no ponto a jusante 2 , junho (J2) estariam dentro dos limites para a classe 1 , que conforme Resolução CONAMA n³57/2005, possui valor máximo de coliformes termotolerantes estipulado em até 200 NMP/100 mL (BRASIL, 2005). A maior parte das amostras ficou com valores iguais ou superiores a 1100 $\mathrm{NMP} / 100 \mathrm{~mL}$ para os Coliformes termotolerantes e E. coli, assim enquadradas em classes 3 ou 4, sendo o limite para a classe 2 de $1000 \mathrm{NMP} / 100 \mathrm{~mL}$ (BRASIL, 2005).

Quadro 5: Valores das análises para os parâmetros microbiológicos para cada amostra nos pontos a montante no verão, em janeiro (M1) e no inverno, mês de junho (M2) e a jusante no verão, em janeiro (J1) e no inverno, em junho (J2) para cada uma das propriedades avaliadas.

\begin{tabular}{|l|l|l|l|l|l|l|l|l|l|l|l|l|}
\hline PARÂMETRO & \multicolumn{3}{|c|}{ COLIFORMES TOTAIS } & \multicolumn{3}{l|}{ COLIFORMES TERMOTOLERANTES } & \multicolumn{3}{|l|}{ E. coli } \\
\hline Propriedade & M1 & J1 & M2 & J2 & M1 & J1 & M2 & J2 & M1 & J1 & M2 & J2 \\
\hline A & 1100 & 1100 & 1100 & 460 & 1100 & 1100 & 43 & 460 & 1100 & 1100 & 43 & 460 \\
\hline B & 1100 & 1100 & 460 & 1100 & 1100 & 1100 & 460 & 460 & 1100 & 1100 & 240 & 460 \\
\hline C & 1100 & 1100 & 460 & 1100 & 1100 & 1100 & 460 & 240 & 1100 & 110 & 460 & 240 \\
\hline D & 1100 & 1100 & 1100 & 240 & 1100 & 1100 & 1100 & 240 & 1100 & 1100 & 38 & 93 \\
\hline E & 1100 & 1100 & 1100 & 1100 & 1100 & 1100 & 1100 & 460 & 1100 & 1100 & 1100 & 460 \\
\hline F & 1100 & 1100 & 1100 & 1100 & 1100 & 1100 & 1100 & 1100 & 1100 & 1100 & 1100 & 460 \\
\hline G & 290 & 1100 & 1100 & 460 & 290 & 1100 & 1100 & 460 & 290 & 1100 & 1100 & 460 \\
\hline H & 1100 & 1100 & 1100 & 460 & 1100 & 290 & 1100 & 150 & 1100 & 290 & 1100 & 150 \\
\hline I & 1100 & 1100 & 1100 & 1100 & 1100 & 1100 & 1100 & 460 & 1100 & 110 & 460 & 460 \\
\hline
\end{tabular}

(M1 - montante janeiro, M2 - montante junho, J1- jusante janeiro, J2 - jusante junho).

Os Coliformes totais não possuem valores estabelecidos nessa resolução. Os Coliformes termotolerantes podem ser usados como valores de referência para a quantidade de Escherichia coli (BRASIL, 2005). 0 quadro 6, abaixo, mostra a quantidade de amostras para em cada propriedade analisada e a suas respectivas classificações nas classes estabelecidas pela Resolução 357/05 do CONAMA (BRASIL,2005) para os parâmetros de Coliformes termotolerantes e E. coli. A maior parte das amostras, sendo 23 para Coliformes termotolerantes, de um total de 36, e 18 para E. coli, respectivamente, ficaram enquadradas em classes 3 ou 4, sugerindo uma concentração microbiológica elevada.

Quadro 6: Quantidade de amostras das propriedades analisadas e sua respectiva quanto às classes da Resolução CONAMA 357/2005.

\begin{tabular}{|c|c|c|c|c|c|c|}
\hline PARÂMETRO & \multicolumn{3}{|c|}{ COLIFORMES TERMOTOLERANTES } & \multicolumn{2}{|r|}{ E. coli } & \multirow[b]{2}{*}{ Classe 3 ou 4} \\
\hline Propr./classe & Classe 1 & Classe 2 & Classe 3 ou 4 & Classe 1 & Classe 2 & \\
\hline $\mathbf{A}$ & 1 & 1 & 2 & 1 & 1 & 2 \\
\hline B & 0 & 2 & 2 & 0 & 2 & 2 \\
\hline $\mathbf{C}$ & 0 & 2 & 2 & 1 & 2 & 1 \\
\hline D & 0 & 1 & 3 & 2 & 0 & 2 \\
\hline $\mathbf{E}$ & 0 & 1 & 3 & 0 & 1 & 3 \\
\hline $\mathbf{F}$ & 0 & 0 & 4 & 0 & 1 & 3 \\
\hline G & 0 & 2 & 2 & 0 & 2 & 2 \\
\hline $\mathbf{H}$ & 1 & 1 & 2 & 1 & 1 & 2 \\
\hline $\mathrm{I}$ & 0 & 1 & 3 & 1 & 2 & 1 \\
\hline Total de amostras & 2 & 11 & 23 & 6 & 12 & 18 \\
\hline
\end{tabular}

Ao se fazer a comparação das médias de todos os parâmetros obtidos por meio das análises físicas, químicas e microbiológicas, para todas as propriedades, aos valores estipulados pela legislação vigente, Resolução CONAMA n³57/2005, podemos verificar as médias de OD, cor, nitrogênio amoniacal, pH e STD encontram-se dentro do estabelecido pela legislação.

O oxigênio dissolvido apresenta uma média acima do limite mínimo estabelecido, que é de $6 \mathrm{mg} / \mathrm{L}$ para classe 1, $5 \mathrm{mg} / \mathrm{L}$ para classe 2 e $4 \mathrm{mg} / \mathrm{L}$ para classe 3 (BRASIL, 2005) em todos os pontos analisados, 
montante e jusante em janeiro (M1 e J1) e montante e jusante em junho (J1 e J2), mostrando uma boa oxigenação da água analisada o que garante um ambiente propício à fauna aquática. A cor encontra-se com todas as médias para todos os pontos (M1, J1, M2, J2) dentro do estabelecido pela resolução, que é de até $75 \mathrm{mg} \mathrm{Pt} / \mathrm{L}$ para a classe 2. A média dos valores do pH está dentro do estabelecido para a legislação (que é de 6 a 9 para classes 1, 2 ou 3) em todos os pontos. A média dos valores de nitrogênio amoniacal encontrase dentro do estipulado pela legislação, sendo que nos dois pontos do mês de junho (montante e jusante M2 e J2) os valores foram iguais a zero. A média dos valores de sólidos totais dissolvidos estão dentro do considerado ideal pela legislação, que é de no máximo $500 \mathrm{mg} / \mathrm{L}$ para todas as classes.

A turbidez a montante no mês de junho (M2) se encontra com uma média de 210,6 NTU, valor acima dos limites estabelecidos pela legislação que são de no máximo 40 NTU para a classe 1 e no máximo 100 NTU, para as classes 2 e 3 . Os valores do ferro na média da jusante no mês de janeiro (J1) é de 8,9 mg/L, estando fora dos limites estabelecidos pela legislação, para todas as classes, que são de no máximo até $0,3 \mathrm{mg} / \mathrm{L} \mathrm{para}$ classe 1 e $5 \mathrm{mg} / \mathrm{L}$ para classes 2 e 3 , sendo enquadrado em classe 4 .

Nas médias dos parâmetros microbiológicos, os valores de coliformes termotolerantes ficaram acima do estipulado para classe 2, que é $1000 \mathrm{NMP} / 100 \mathrm{~mL}$ no ponto a jusante em janeiro (J1), sendo que nos demais pontos ficaram dentro do limite para essa classe. Já a média dos valores de $E$. coli no montante em janeiro (M1) estão acima do limite permitido pela legislação (Tabela 1).

Tabela 1: Média total dos parâmetros físicos, químicos e microbiológicos nos pontos a montante e a jusante dos recursos hídricos nas propriedades produtoras de leite avaliadas.

\begin{tabular}{|c|c|c|c|c|}
\hline PARÂMETROS & & MÉDIAS & & \\
\hline & M1 & J1 & M2 & $\mathrm{J} 2$ \\
\hline Cor verdadeira $(\mathrm{Pt} / \mathrm{L})$ & 30,0 & 34,7 & 14,9 & 14,9 \\
\hline Temperatura $\left(\mathrm{C}^{\circ}\right)$ & 22,8 & 22,8 & 17,2 & 17,0 \\
\hline $\mathrm{pH}$ & 7,4 & 7,4 & 6,9 & 6,8 \\
\hline Turbidez (NTU) & 98,5 & 37,5 & 210,6 & 52,0 \\
\hline Oxigênio Dissolvido (mg/L) & 13,7 & 12,9 & 17,2 & 17,2 \\
\hline Sólidos Totais Dissolvidos (mg/L) & 77,2 & 70,6 & 59,8 & 67,7 \\
\hline Nitrogênio amoniacal (mg/L) & 0,5 & 0,2 & 0,0 & 0,0 \\
\hline Ferro (mg/L) & 3,2 & 8,9 & 1,0 & 0,8 \\
\hline Coliformes totais (NMP/100 mL) & 1010,0 & 1100,0 & 957,8 & 791,1 \\
\hline Coliformes termotolerantes (NMP/100 mL) & 270,0 & 1010,0 & 840,3 & 447,8 \\
\hline E. coli $(\mathrm{NMP} / 100 \mathrm{~mL})$ & 1010,0 & 790,0 & 626,8 & 360,3 \\
\hline
\end{tabular}

Legenda: M1- montante janeiro M2- montante junho $p=$ NS e J1- jusante janeiro e J2-jusante junho.

\section{DISCUSSÃO}

O potencial Hidrogeniônico $(\mathrm{pH})$ é a concentração de hidrogênio em uma determinada solução e é utilizado para mensurar o grau de acidez e/ou de alcalinidade das amostras. Esse parâmetro é essencial para a avaliação de recurso hídrico (HERMES et al., 2004), devido à influência que o mesmo pode provocar em algumas substâncias atenuando ou intensificando seus efeitos (CETESB, 2016).

No que se refere a influencia no $\mathrm{pH}$ devido às estrumeiras, as análises mostram que não houve diferenças significativas nos pontos a montante e a jusante no mesmo mês de coleta, conforme citado acima, podendo-se concluir que a forma como as estrumeiras ou os dejetos estão dispostos nas propriedades não interferem no $\mathrm{pH}$ da água. Os rios brasileiros tendem a apresentar pH que varia de neutro a ácido. Valores 
abaixo de 7,0 e próximos a 0, indicam aumento de acidez e valores na escala de 7,0 a 14,0 indicam aumento da alcalinidade (VON SPERLING, 2005).

Essa diminuição do pH no mês frio, ou seja, junho, pode ser devido ao despejo de esgoto doméstico, não necessariamente dentro da propriedade, sendo que os valores de montante e jusante no mesmo mês não apresentam diferenças significativas, o que descarta a influência das estrumeiras. Para Marmontel et al. (2015), as alterações nos valores de pH podem ser provocadas por despejos industriais e domésticos. Nos locais onde ocorre a liberação desses despejos se pode observar uma diminuição do pH devido ao aumento nas concentrações de ácidos orgânicos.

Os valores observados para a temperatura mostram uma diminuição no mês de junho, algo já esperado em se tratando de um mês mais frio do que janeiro. Essas diferenças poderiam ter sido maiores, pois tanto o mês de janeiro quanto o mês de junho foram atípicos em suas temperaturas, sendo que no ano das coletas, 2019, o mês de janeiro foi chuvoso e com temperatura mais amena e o mês de junho foi quente e com poucas chuvas. O regime de chuvas influenciou também o nível dos cursos d’água que ficou muito parecido nos dois meses analisados, mesmo sendo estações do ano contrastantes (verão e inverno). Amorim et al. (2017), observaram uma marcante variação da temperatura da água ao longo do período amostral em seu estudo, sendo que a elevação da temperatura pode ser atribuída à redução da precipitação pluviométrica e aumento da radiação solar no período de análise.

A temperatura não tem valores afixados na legislação, mas a mesma pode influenciar outros aspectos da água, como viscosidade e condutibilidade (CETESB, 2014) e de acordo com Von Sperling (2005), as elevações da temperatura são responsáveis pelo aumento da taxa de reações físicas, químicas e biológicas, diminuindo a solubilidade dos gases, como o oxigênio dissolvido, por exemplo. A análise bioestatística demonstrou também que não ocorrem diferenças de temperatura da água dentro do mesmo período, ou seja, montante e jusante de janeiro e montante e jusante de junho. Algo também já esperado, devido às coletas terem ocorrido no mesmo dia e horário.

A vegetação em torno dos cursos d’água auxilia a manter a temperatura da água mais baixa, isso mostra a importância da presença da vegetação ciliar. A presença da mata ciliar é a maneira mais efetiva de prevenir aumentos da temperatura da água, oferecendo maior proteção ao ambiente aquático, devido à menor exposição à luz solar direta (MARMONTEL et al., 2015). Mesmo que algumas propriedades possuam a mata ciliar completamente degradada, a temperatura não foi influenciada por isso. O período do dia em que a temperatura da água é medida também pode influenciar, sendo que todas as coletas e medições de temperatura desse estudo ocorreram no mesmo período do dia, ou seja, pela manhã, em horários que variaram das 8 às 11 horas.

O valor mínimo de cor verdadeira observado dentre todas as amostras foi de 1,6 mg Pt/L para a amostra A no ponto a jusante no mês de junho (J2), conforme o Quadro 3. A propriedade C, correspondente à amostra C (J1), possui estrumeira fechada e coberta, porém fica próxima da margem do córrego, correspondente ao ponto montante da propriedade e apesar da vegetação ciliar estar preservada, encontrase bastante estreita, composta de, no máximo, 1,5 metros. Isso pode estar relacionado ao nível elevado de 
cor verdadeira nessa amostra. O recurso hídrico da amostra A é uma nascente e o ponto a jusante, corresponde a um local onde há uma plantação de soja, porém existe uma vegetação nativa em seu entorno, mantendo o recurso hídrico bastante preservado. Em se tratando de uma lavoura, os animais não circulam por aí, mas sim na parte anterior ao ponto de coleta. As cores das águas naturais podem sofrer influência de compostos orgânicos que são provenientes da decomposição da matéria-orgânica vegetal como resultado do metabolismo de microrganismos oriundos das atividades antrópicas (LIBÂNIO, 2010). Sua alteração é o primeiro sinal de contaminação na água, estando essa associada ao grau de redução de intensidade que a luz sofre ao atravessá-la, que se se deve, em geral, a presença de sólidos dissolvidos (SAMPAIO et al., 2019).

As análises de ferro mostraram que 72 \% das amostras ficaram enquadradas na classe 3 , que possui limite de $5 \mathrm{mg} / \mathrm{L}$ e apenas 6 amostras ficaram dentro dos limites para as classes 1 e 2 que é de 0,3 mg/L. Richter e Neto (2013), afirmam que no Brasil é muito comum encontrar valores de ferro elevado nas águas superficiais ou subterrâneas, devido ao mesmo estar combinado à matéria-orgânica em estado coloidal, ou ainda em águas poluídas por resíduos industriais. Os íons de ferro presentes em águas destinadas ao abastecimento humano ou animal podem causar incrustações, possibilitando o aparecimento de bactérias ferruginosas nocivas (MORUZZI et al., 2012). Para Miranda et al. (2017), o aumento da concentração desse elemento pode estar associado a diversos fatores observados no campo, como por exemplo, o processo avançado de erosão e assoreamento observados nos ambientes aquáticos. O ferro existente nas amostras pode ter sua origem no solo, devido ao mesmo ser basáltico na região do VT, local do presente estudo.

Marmontel et al. (2015) verificaram que os valores elevados de ferro na água foram maiores em locais onde não há vegetação ciliar, sendo que a ausência ou somente uma faixa da vegetação ciliar em estado degradado contribui para a elevação dos valores de ferro. A amostra D, conforme já citado, possui margem completamente degradada, o que promove a erosão e a deposição de sedimentos no local, o que poderia explicar níveis de ferro tão elevados. Além disso, o fato de não possuir estrumeira pode fazer com que a matéria-orgânica existente nos dejetos produzidos pelos animais alcancem a nascente.

Os valores de turbidez encontram-se alterados para parte das amostras analisadas (Propriedades A, I, D e H). O aumento da turbidez pode estar relacionado à poluição causada por esgoto doméstico ou outros despejos, como efluentes industriais. Quando a turbidez se encontra elevada, a mesma reduz a penetração da luz na água e como consequência diminui a fotossíntese dos organismos presentes (CETESB, 2014). A propriedade $A$ (amostra A), em seu ponto a montante, possui características bem diferentes do seu ponto a jusante (conforme citado acima, nos dados sobre cor verdadeira). O local é muito próximo de onde estão os animais da propriedade, porém longe da estrumeira, que é do tipo fechada e coberta. O local é composto por pastagem, sem vegetação nativa em seu entorno, o que pode justificar o valor elevado de turbidez nesse local.

Assim como na propriedade A, a propriedade D também é apresenta uma nascente, que é usada em alguns momentos para dessedentação dos animais que circulam pelo local, composto de uma pastagem sem vegetação nativa nas margens da água, que se encontra completamente degradada. O aspecto da água era também muito característico e diferente dos demais locais (propriedades) analisados nesse estudo, 
possuindo muitas espumas, e por não possuir vegetação, muito sedimento no fundo, sendo até mesmo difícil de realizar a coleta das amostras. Isso pode estar relacionado aos níveis elevados para a turbidez nos dois pontos analisados no mês de junho. As propriedades I e H são córregos não utilizados para a dessedentação dos animais e com vegetação brevemente preservada. Quanto à forma de acondicionamento dos dejetos, as propriedades A, I e H, possuem estrumeira, sendo na propriedade I sem cobertura. Já na propriedade D não há estrumeira, o que também pode contribuir para o aumento dos níveis de turbidez.

As análises de sólidos totais dissolvidos, no presente estudo, mostraram que todas as amostras estão dentro do limite estabelecido pela legislação para a classe 2 , sendo que o estipulado é de até $500 \mathrm{mg} / \mathrm{L} \mathrm{para}$ as águas de classes 1, 2 ou 3. Os valores máximo e mínimo de STD encontrados nesse estudo foram, respectivamente, $114,3 \mathrm{mg} / \mathrm{L}$ na amostra I no ponto jusante janeiro (J1) $0,0 \mathrm{mg} / \mathrm{L}$ para a amostra $\mathrm{C}$ também no ponto jusante em janeiro (J1). Os STD são compostos, principalmente em forma de íons, que podem ser gerados a partir do intemperismo (PIRATOBA et al., 2017).

As análises de oxigênio dissolvido demostram boa oxigenação das águas. Oliveira, Santos e Lima (2016), em seu estudo no riacho São Caetano (MA), constataram que todas as suas amostras estavam acima de $5,0 \mathrm{mg} / \mathrm{L}$ e assim, de acordo com os limites estabelecidos pela resolução do CONAMA no 357/2005 (CONAMA, 2005) para corpos d'água de classe 2. Muller et al. (2016), em seu estudo com a água do Rio Taquari - RS, também observaram que os valores de OD dos pontos analisados ficaram dentro do estabelecido pela legislação, porém os resultados para a turbidez mostraram níveis acima de 100 NTU, limite máximo estabelecido para classes 2, 3 ou 4. Esses dois parâmetros estão em consonância com o observado no presente estudo, sendo importante ressaltar que os cursos d’água analisados nas propriedades são afluentes do Rio Taquari, compondo a bacia Taquari-Antas.

Na maioria dos pontos das propriedades analisadas nesse estudo, cerca de $77 \%$ do total, os valores de OD foram acima de $10 \mathrm{mg} / \mathrm{L}$. Valores acima de $10 \mathrm{mg} / \mathrm{L}$ de OD podem indicar o desenvolvimento anormal de algas, possivelmente devido à eutrofização dessas águas, caracterizando uma situação na qual pode haver supersaturação de nutrientes. Porém, além da fotossíntese, o oxigênio também é introduzido nas águas por meio de processos físicos, que dependem das características hidráulicas dos corpos d'água, como por exemplo, a velocidade da água (ANA, 2009). Os cursos hídricos analisados nesse estudo apresentam grande velocidade na água, alguns até mesmo com quedas d'água próximas aos locais analisados, com exceção da propriedade $\mathrm{D}$ que possuí água com pouca movimentação.

As análises microbiológicas demostram que propriedade analisadas possuem classificação entre 3 e 4 para esses parâmetros. Isso demostra níveis elevados de coliformes termotolerantes e E. coli. Em se tratando de recursos hídricos oriundos de propriedades rurais, em alguns casos, locais de difícil acesso devido à vegetação ciliar e com densidade populacional baixa os níveis das análises microbiológicas podem ser considerados elevados. Segundo Pessoa et al. (2018) em seu estudo sobre a qualidade da água de rios da Bahia, apenas os locais com menor quantidade de habitantes ficaram dentro dos limites estabelecidos pela Resolução CONAMA 357/2005, pois sugerem baixa geração de esgoto doméstico. Isso contrasta com o observado nesse estudo. 
Os valores elevados de coliformes termotolerantes podem ser associados ao despejo de efluentes ou matéria-orgânica em geral e é considerada a principal causa de contaminação das águas (DOI et al., 2015). Já a presença de níveis elevados de E. coli na água pode estar associado ao despejo de material fecal na água. Esses dados sugerem que de alguma forma essas águas vem sendo contaminadas com matéria de origem fecal, humana ou animal. Em diversas propriedades, os produtores relatam que nas propriedades vizinhas estaria sendo liberando dejetos, provenientes principalmente de suinocultura, nos corpos d'água e que isso ocorre com maior frequência em períodos chuvosos. Apesar disso, não se observou diminuição da quantidade de $\mathrm{OD}$, que pode ser explicada pela alta velocidade desses cursos hídricos. A classificação dessas águas, levando-se em conta todos os parâmetros que foram analisados fica estipulado em classes 3 ou 4 em todas as propriedades.

Outra situação a ser levada em consideração é que as análises de nitrogênio amoniacal foram iguais a zero para quase todas as amostras. Isso não significa que não há nitrogênio sob outras formas na água, ou seja, já convertidos em nitrito ou nitrato. Conforme a CETESB (2016), os esgotos sanitários constituem a principal fonte de nitrogênio na água. O nitrogênio pode ser encontrado nas águas nas formas de nitrogênio orgânico, amoniacal, nitrito e nitrato. As duas primeiras são formas reduzidas e as duas últimas, oxidadas, caso a amostra apresentar predominância das formas reduzidas significa que o foco de poluição se encontra próximo e caso se prevalecerem o nitrito e o nitrato, denota que as descargas de esgotos se encontram distantes. Os esgotos também são fontes de microrganismos. Apesar dos níveis de coliformes totais, termotolerantes e $E$. coli estarem elevados, as estrumeiras, ou ainda os locais de deposição de dejetos não alteram significativamente os níveis a jusante nas propriedades em relação aos pontos a montante. 0 mesmo ocorre para as análises físicas e químicas.

Ahlert (2015), em seu estudo sobre a sustentabilidade em propriedades produtoras de leite do Vale do Taquari, constatou que os dejetos foram o destaque negativo, sendo o maior responsável pela baixa sustentabilidade das propriedades avaliadas. Os produtores sem estrumeira e os que possuem estrumeira fechada e sem cobertura, que ocasiona o contato com a chuva, impedindo o adequado período de descanso dos dejetos e aumentando os riscos de contaminação de cursos d'água, demonstraram os resultados mais negativos em seus índices. Apesar disso, nesse estudo, níveis fora do estabelecido pela legislação foram observados até mesmo nas propriedades com estrumeira, seja apenas fechada ou fechada e com cobertura. Isso ocorreu tanto a montante quanto a jusante nas propriedades. A utilização de estrumeiras é de extrema importância devido à minimização dos impactos causados pela geração de resíduos, e conforme citado acima, ainda melhor se forem do tipo fechadas e com cobertura, para evitar que os dejetos possam ser levados pela chuva. Para Nardi et al. (2015), a produção de leite pode causar vários impactos ao meio ambiente, porém, estes podem ser minimizados se adotando técnicas adequadas para os resíduos gerados, fazendo com que pequenas propriedades rurais possam se tornar sustentáveis ecologicamente.

A quantidade de produção nas propriedades analisadas também pode estar relacionada, sendo que propriedades sem estrumeira podem não a possuir devido à produção ser menor que nas propriedades com estrumeira. Uma geração maior de resíduos, em propriedades com maior produção, pode vir a interferir na 
qualidade dos recursos hídricos da propriedade, mesmo quando acondicionados em estrumeiras.

\section{CONCLUSÕES}

A análise dos parâmetros físicos e químicos demostraram que para a maioria dos parâmetros analisados a água está classificada entre as classes 1 e 2 conforme a Resolução CONAMA n 357/2005 para a maior parte das amostras, com exceção do ferro, classificado em classe 3. As análises dos parâmetros microbiológicos mostram que a maior parte das amostras coletadas nas propriedades possuem valores de coliformes termotolerantes e $E$. coli enquadrados em classes 3 ou 4. Isso demonstra que essas águas, mesmo sendo oriundas de locais pouco habitados, estão sendo contaminadas com matéria-orgânica, que podem ser provenientes de propriedades vizinhas ou mesmo ser gerada pela própria propriedade e de alguma forma atingir os pontos a montante.

O presente estudo demostrou que não há diferenças estatísticas nos parâmetros físicos, químicos e microbiológicos analisados dos pontos montante e jusante das propriedades e também que não ocorre interferência nos níveis dos parâmetros em diferentes meses do ano, sendo um no verão, período quente mês de janeiro e outro no inverno, período frio, mês de junho, esse estudo não mostrou diferenças significativa para a maioria dos parâmetros físicos e químicos.

Pode-se concluir que a água das propriedades produtoras de leite analisadas, apresenta qualidade, principalmente microbiológica, comprometida. É necessário um trabalho de conscientização junto aos produtores e agricultores da região para que acondicionem de forma adequada os dejetos produzidos em suas propriedades, pois a preservação dos recursos hídricos é de extrema importância, não apenas para a fauna e a flora, como também para o próprio ser humano.

\section{REFERÊNCIAS}

AHLERT, E. M.. Sistema de indicadores para avaliação da sustentabilidade de propriedades produtoras de leite. Dissertação (Mestrado) - Universidade do Vale do Taquari, Lajeado, 2015.

APHA. American Public Health Association. Standard Methods for the Examination of Water and Wastewater. 22 ed. Washington: APHA, 2012.

AMORIM, D. G.; PAULO ROBERTO SARAIVA CAVALCANTE, P.R.S.; SOARES, L.S.; AMORIM, P.E.C. Enquadramento e avaliação do índice de qualidade da água dos igarapés Rabo de Porco e Precuá, localizados na área da Refinaria Premium I, município de Bacabeira (MA). Engenharia Sanitária e Ambiental, Rio de Janeiro, v.22, n.2, p.251-259, 2017.

ANA. Agência Nacional de Águas. Indicadores de Qualidade índice de qualidade das águas. Brasília: ANA, 2009.

BRASIL. Novo código florestal, Lei n. 12.651. Dispõe sobre a proteção da vegetação nativa; altera as Leis n.s 6.938, de 31 de agosto de 1981, 9.393, de 19 de dezembro de 1996, e 11.428, de 22 de dezembro de 2006; revoga as Leis n.s 4.771, de 15 de setembro de 1965, e 7.754, de 14 de abril de 1989, e a Medida Provisória n. 2.166-67, de 24 de agosto de
2001; e dá outras providências. Brasília: DOU, 2012.

BORTOLI, J; SALVI, L. C.; SANTANA, E. R. R.; REMPEL, C.. Qualidade microbiológica da água em estabelecimentos rurais no Vale do Taquari-RS. In: SIMPÓSIO BRASILEIRO DE RECURSOS HÍDRICOS, 21. Anais. Brasília, 2015.

BORTOLI, J; SANTANA, E. R. R.; REMPEL, C.. Caracterização de estabelecimentos rurais com ênfase na pecuária leiteira no vale do Taquari-RS. Ambiência Guarapuava (PR), v.12, n.1, p.87-100, 2016.

BORTOLI, J.; SANTANA, E. R. R.; REMPEL, C.. Manejo do dejeto bovino e qualidade da água de poços próprios em estabelecimentos rurais do Vale do Taquari/RS. In: SIMPÓSIO BRASILEIRO DE RECURSOS HÍDRICOS, 21. Anais. Brasília, 2015.

CONAMA. Conselho Nacional do Meio Ambiente. Resolução n. 357, de 17 de março de 2005. Dispõe sobre a classificação dos corpos de água e diretrizes ambientais para o seu enquadramento, bem como estabelece as condições e padrões de lançamento de efluentes, e dá outras providências. Brasília: DOU, 2005. 
CETESB. Companhia Ambiental do Estado de São Paulo. Apêndice $D$ Significado Ambiental e Sanitário das variáveis da Qualidade da água. São Paulo: CETESB, 2014.

CETESB. Companhia Ambiental do Estado de São Paulo. Apêndice E Significado Ambiental e Sanitário das Variáveis de Qualidade das Águas e dos Sedimentos e Metodologias Analíticas e de Amostragem. São Paulo: CETESB, 2016.

DOI, S. A.; OLIVEIRA, A. J. F. C.; BARBIERI, E.. Determinação de coliformes na água e no tecido mole das ostras extraídas em Cananéia, São Paulo, Brasil. Engenharia Sanitária e Ambiental, Rio de Janeiro, v.20, n.1, p.111-118, 2015.

FAO. Food and Agriculture Organization of the United Nations. Statistic Division. Roma: FAOSTAT, 2016.

FEE. Fundação de Economia e Estatística. Aglomeração produtiva de laticínios na região do Corede Vale do Taquari. Porto Alegre: FEE, 2017.

FUNASA. Fundação Nacional de Saúde. Ministério da saúde. Manual Prático de Análise de Água. 4 ed. Aracaju: FUNASA, 2013.

IBGE. Instituto Brasileiro Geografia Estatística. Produção da Pecuária Municipal, 2016. Rio de Janeiro: IBGE, 2017.

JUNG, C. F.; JUNIOR, A. M.. Produção leiteira no Brasil e características da bovinocultura leiteira no Rio Grande do Sul. Revista de História e Geografia Ágora, Santa Cruz do Sul, v.19, n.1, p.34-47, 2017.

LIBÂNIO, M.. Fundamentos de qualidade e tratamento de água. 3 ed. Campinas: Átomo, 2010.

MARION FILHO, P. J.; FAGUNDES, J. O.; SCHUMACHER, G.. A produção de leite no Rio Grande do Sul: produtividade, especialização e concentração (1990 - 2009). Revista de Economia e Agronegócio, Santa Maria, v.9, n.2, 2011.

MAGALHÃES, Y. A.; BATISTA, A. S. M.; FONTENELLE, R. O. S.; JULIÃO, M. S. S.; LOIOLOA, P. M. G.; MESQUITA, R. M.; AGUIAR, F. L. L.; OLIVEIRA, A. R.. Avaliação microbiológica e físico-química da água dos açudes urbanos utilizados na dessedentação animal em Sobral, Ceará. Revista da Universidade Vale do Rio Verde, v.12, n.2, p.141-148, 2014

MARMONTEL, C. V. F.; RODRIGUES, V. A.. Parâmetros Indicativos para Qualidade da Água em Nascentes com Diferentes Coberturas de Terra e Conservação da Vegetação Ciliar. Floresta Ambiental, Seropédica, v.22, n.2, p.171-181, 2015.
MIRANDA, C.; ROSA, L.; BONITO, J.; JUNIOR, A.; VEIGA, N.; OLIVEIRA, F.; BARROS, B.. Uso e qualidade da água na microbacia hidrográfica do rio Parafuso (Moju, Pará, Brasil) . Revista Recursos Hídricos, v.38, n.2, p.51-62, 2017.

MORUZZI, R. B.; REALI, M. A. P.. Oxigenação e Remoção de Ferro e Manganês em Águas para Fins de Abastecimento Público ou Industrial: Uma Abordagem Geral. Revista de Engenharia e Tecnologia, São Carlos, v.4, n.1, 2012.

MULLER, T.; GRANADA, C. E.; SPEROTTO, R. A.. Qualidade da água de três locais com potenciais fontes de contaminação no Rio Taquari, RS. Revista Ambiente e Água, Taubaté, v.11, n.1, p.75-84, 2016

NARDI, A. C.; LOCH, P.; CONTO, A. G.; MENEGHATTI, M. R. Análise dos impactos ambientais da pecuária de leite em uma pequena propriedade rural. In: SINGEP, 4. Anais. São Paulo, 2015

OLIVEIRA, R. M. M.; SANTOS, E. V.; LIMA, K. C.. Avaliação da qualidade da água do riacho São Caetano, de Balsas (MA), com base em parâmetros físicos, químicos e microbiológicos. Eng. Sanit. Ambient., Rio de Janeiro, v.22, n.3, p.523-529, 2017.

PESSOA, J. O.; ORRICO, S. R. M.; LORDELO, M. S.. Qualidade da água de rios em cidades do Estado da Bahia. Engenharia Sanitária e Ambiental, Rio de Janeiro, v.23, n.4, p.687696, 2018.

PIRATOBA, A. R. A.; RIBEIRO, H. M. C.; PIRATOBA, G. M.; GOLÇALVES, W. G.. Caracterização de parâmetros de qualidade da água na área portuária de Barcarena, PA, Brasil. Ambiente e Água, Taubaté, v.12, n.3, 2017.

REMPEL, C.. A ecologia de paisagem e suas ferramentas podem aprimorar o zoneamento ambiental?: o caso da região política do Vale do Taquari. Tese (Doutorado em Ecologia) - Universidade Federal do Rio Grande do Sul, Campo Grande, 2009.

RICHTER, C. A.; NETTO, J. M. A.. Tratamento de água: tecnologia atualizada. São Paulo: Edgard Blücher, 2013.

SAMPAIO, C. A. P.; IDE, G. M.; BATALHA, C. P.; PEREIRA, L. C.; BUENO, L. F.. Análise técnica de água de fontes rurais. Engenharia Sanitária e Ambiental, Rio de Janeiro, v.24, n.2, p.213-217, 2019.

VON SPERLING, M.. Introdução à Qualidade das Águas e Tratamento de Esgotos. 3 ed. Belo Horizonte: Universidade Federal de Minas Gerais, 2005.

A CBPC - Companhia Brasileira de Produção Científica (CNPJ: 11.221.422/0001-03) detém os direitos materiais desta publicação. Os direitos referem-se à publicação do trabalho em qualquer parte do mundo, incluindo os direitos às renovações, expansões e disseminações da contribuição, bem como outros direitos subsidiários. Todos os trabalhos publicados eletronicamente poderão posteriormente ser publicados em coletâneas impressas sob coordenação da Sustenere Publishing, da Companhia Brasileira de Produção Científica e seus parceiros autorizados. Os (as) autores (as) preservam os direitos autorais, mas não têm permissão para a publicação da contribuição em outro meio, impresso ou digital, em português ou em tradução. 